\title{
Strategies for integrating reinforcement into 3D concrete printing at TU Dresden
}

Egor Ivaniuk ${ }^{1[\mathrm{https}: / / o r c i d . o r g / 0000-0002-0905-9557]}$ Steffen Müller ${ }^{1[\mathrm{https}: / / \text { orcid.org/0000-0002-0630-5441] }}$ Neef $^{1 \text { [https://orcid.org/0000-0002-8256-1455] }}$, and Viktor Mechtcherine ${ }^{1[\mathrm{https}: / / \text { orcid.org/0000-0002-4685-7064] }}$

\footnotetext{
${ }^{1}$ Technische Universität Dresden, Germany
}

Abstract. 3D concrete printing (3DCP) has all the chances to become the future of the construction industry, but this technology is not yet widely applicable. One of the main challenges still to be mastered is the difficulty of reinforcing printed structures. At this point, many reinforcement strategies have already been proposed, which are fully or partially capable of solving the problem. This publication provides first an overview of existing reinforcement strategies, classified according to the time of reinforcement introduction: before, during, or after 3D printing. Then the authors present the approaches developed at TU Dresden and provide readers with information on new methods that still are in the development stage.

Keywords: Digital Construction, Digital Concrete, Additive Manufacturing, 3D Concrete Printing, Reinforcement

Conference presentation video: https://doi.org/10.5446/56110

\section{Introduction}

The need for qualitative changes in the construction sector has been growing for a long time. The main reasons for this are the global technological progress, the increasing need for affordable housing, low productivity in construction works and scarcity of skilled workers in many countries [1]. While other industries such as the automotive and appliance industry have already moved to a high degree of automation, most construction projects are still carried out using manual labor. This can be changed by introducing new automated digital technologies into construction.

A number of technologies, that enable to achieve high automation of construction, have already been developed, such Smart Dynamic Casting [2], Mesh Mold [3], automated brick-laying [4], and Additive Manufacturing techniques [5] including 3D concrete printing based on layered extrusion [6], material jetting [7], and particle-bed binding [8]. At the moment 3D concrete printing technologies seem to be most promising, as can be concluded from the numerous construction projects completed worldwide [9]. They have all chances to become the future of the industry, offering faster construction, less manual work and more safety for workers, saving materials, and reducing the cost [10].

However, 3D concrete printing still has a number of problems that hinder its further development. One of the most major challenges is the absence of an ultimate solution for the reinforcement of 3D printed structures, that could be automated and would enable to sufficiently reinforce the printed structure in all required directions. Conventional reinforcement, which until now has mainly been used in 3D concrete printing projects, limits design freedom and requires manual installation and therefore does not allow for a high level of automation. 
That is why researchers are currently trying to find alternative methods of reinforcement that would bring 3D printing technology to its full potential. This publication provides a brief overview of already existing approaches for reinforcement of 3D printed concrete structures and presents the state of current research at TU Dresden in this field.

\section{Existing reinforcement strategies in 3D concrete printing}

While no ultimate solution for fully automated reinforcing in 3D concrete printing has yet been developed, many reinforcement strategies have already been demonstrated; see e.g. [11][16]. The possibilities for reinforcement integration can greatly vary depending on the chosen digital construction process. Rather than describe the reinforcement strategies for different existing digital construction technologies, as it has been presented already in earlier publications, this paper will focus on the strategies applicable for 3D printing by layer-by-layer extrusion only. Thus, it can serve as a kind of a catalogue of existing and developing methods of reinforcement integration for this technology. The next three sections present the existing reinforcement strategies divided into three groups depending on the time of reinforcement introduction: before, during, and after 3D printing.

\section{Introduction of reinforcement prior concrete printing}

HuaShang Tengda company demonstrated the use of pre-installed steel meshes for the construction of vertical walls [17]; see Fig. 1a. Mesh reinforces a wall simultaneously in two directions, and, since this reinforcement is similar to the wall reinforcement in traditional concrete construction, this strategy can simplify the process of government approval, however, provided there are no cavities and good adhesion between the concrete and the reinforcement. The disadvantages of this reinforcement method are the need for a special printer with a huge bifurcated printhead and limited design freedom. The maximum height of the used reinforcement mesh is limited by the height of the bifurcated part, so a pause in the 3D printing process may be required to build up the mesh at the top.

A pre-installed mesh also can be used as a support for printing inclined and curved structures. The possibility of printing on meshes was proved as a part of the SCRIM project [18], where they used tightly fixed fine textile meshes for 3D printing of various patterns; see Fig. $1 b$.

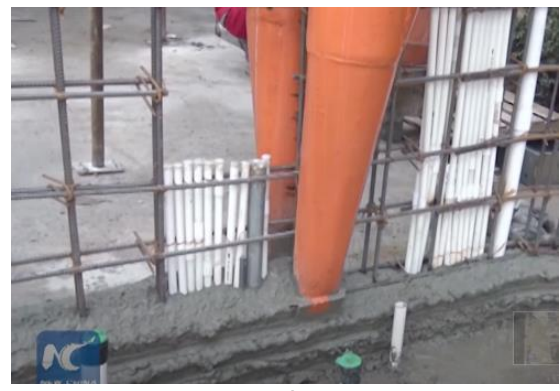

a)

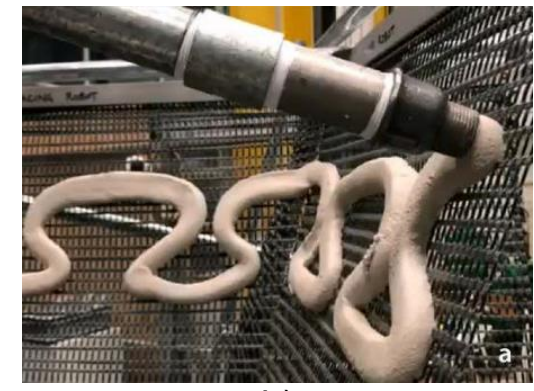

b)

Figure 1. Introduction of reinforcement prior concrete printing: a) 3D printing around the steel meshes using bifurcated printhead [17] and b) extrusion-based material deposition on a fine textile mesh [18].

\section{Reinforcement integration during concrete printing}

The ability to integrate reinforcement during printing will allow 3D printing technology to fully reveal its potential in automation and construction speed, which is why much research has been being carried out in this area. So far, the following strategies for integrating reinforcement during concrete printing have been presented: 
1) Reinforcement with bars:

- Placement of bars in between the printed layers [19]; see Fig. 2a. The automated installation of long bars is difficult due to their bending and vibration.

- Welding of short bars [20]. With the use of a twin nozzle, the bars can also be installed in the vertical direction; see Fig. $2 b$. Positioning of short bars is more precise than long ones, however, the automation of this technology is challenging and has not yet been implemented.

2) Placement of meshes and textiles for bi-directional reinforcement:

- Horizontal placement of steel meshes in between the printed layers. For contour crafting $3 \mathrm{D}$ printing technology, where only the outer edges of the walls are printed for subsequent filling, this mesh allows the printed edges of the walls to be held together; see Fig. 2c.

- Narrow textile mesh is installed vertically between layers, requiring the use of a special split nozzle [21]; see Fig. 2d. The diameter of wires in the used mesh must be small enough to provide the flexibility required to automate the mesh installation process.

- Placement of textile in between the layers [22] for the production of a reinforced beam with 3D printing; see Fig. $2 \mathrm{e}$.

3) Entraining of a cable into the printing layer. With this technology, the structure is reinforced only in the direction of printing, and the cable cross-section is limited since it must be sufficiently flexible. A system for the automated insertion of cables into extruded filament was presented at TU Eindhoven [23]; see Fig. $2 f$.

4) Penetration reinforcement to provide bond across the printed layers and available for full automation:

- Pressing or shooting nails [24], short bars [25], [26], wire fibers [26] or staples [27] into printed layers; see Fig. $2 \mathrm{~g}$. These methods of introducing reinforcement, however, can damage the printed structure and can result in poor adhesion between the reinforcement and the concrete [11].

- Insertion of screws by a combination of pressing and rotation; see Fig. $2 \mathrm{~h}$. The research conducted by Hass and Bos [28] showed a high quality of the bond between screws and printed concrete.

5) Short fibers dispersed within 3D printing material; see Fig. 2i. Because of their discontinuity, short fibers can hardly provide sufficient reinforcement, however, they are easy to use, protect the printed structure from cracking, and can be combined with virtually any other reinforcement technology.

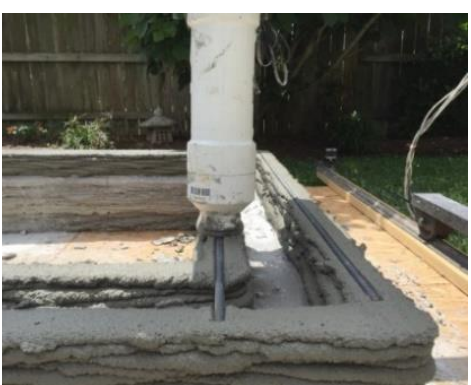

a)

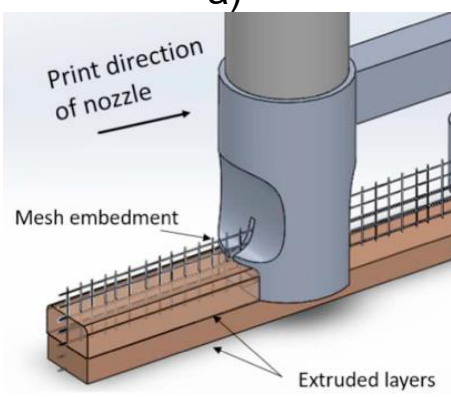

d)

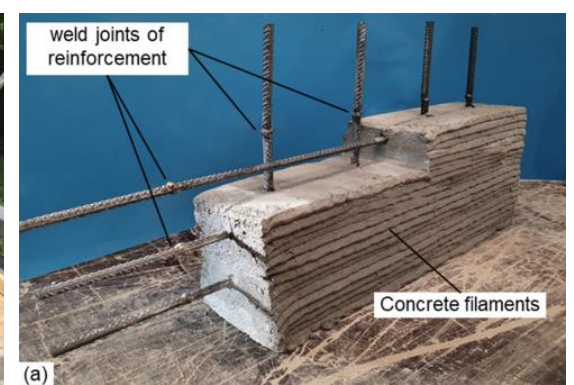

b)

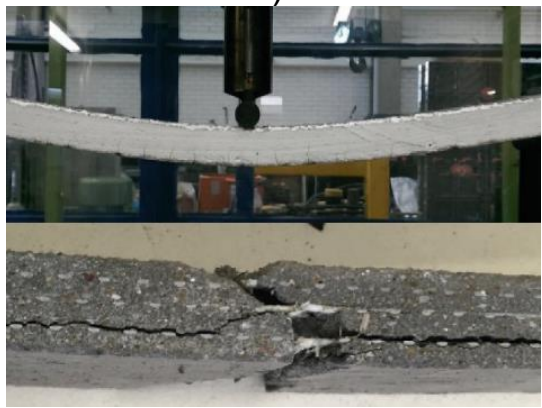

e)

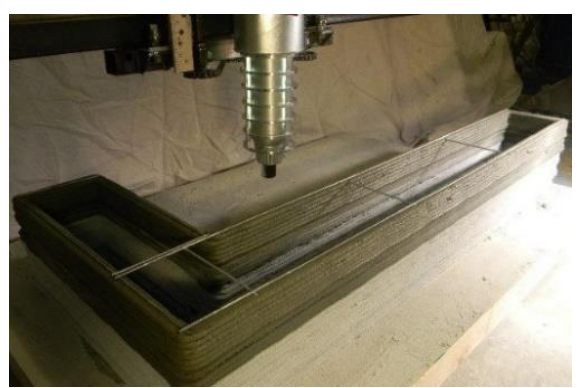

c)

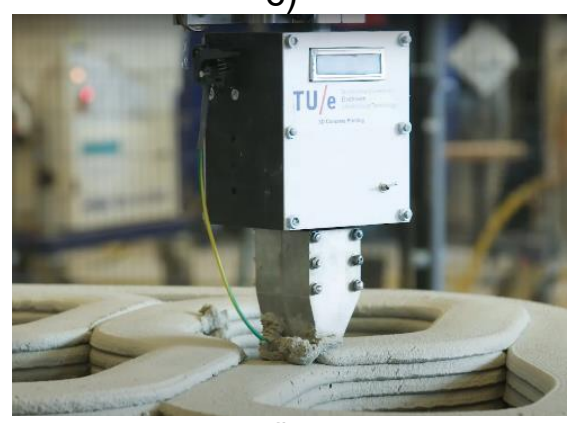

f) 


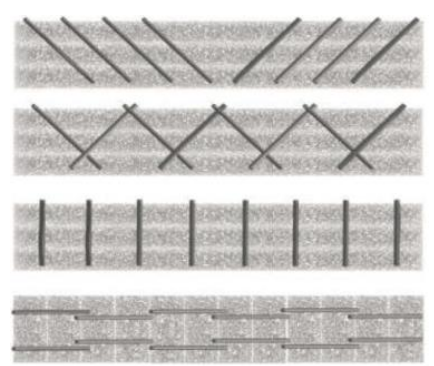

g)

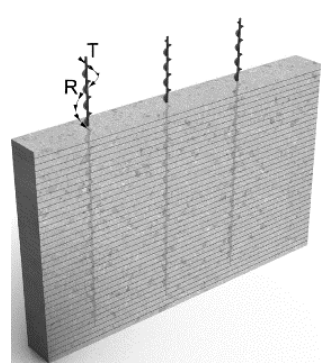

h)

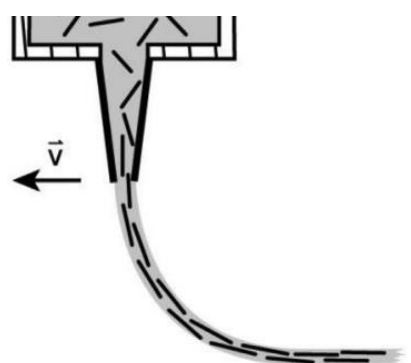

i)

Figure 2. Reinforcement integration during concrete printing with a) conventional steel bars [29], b) welding of short bars [20], c) steel mesh [30], d) textile mesh [21], e) AR-glass textile [22], f) steel cable [31], g) nails [24], h) screws [28], and i) short fibers [32].

\section{Reinforcement integration after concrete printing}

After 3D concrete printing, reinforcing bars can be placed in specially created cavities and in certain cases post-tensioned. This method was used to reinforce individual structural elements [33], or entire structures consisting of several 3D printed segments, as demonstrated in the construction of bridges [34], [35]; see Fig. 3a.

External reinforcement system is another approach developed by Asprone et al. [36]. In their study, a beam was produced from variable 3D printed modules, connected to each other by steel bars; see Fig. 3b.

Pre-fabricated cages are currently the most widely used reinforcement for the construction of columns with 3D printing. For this only the outer edge of the structure is printed that serves as a stay-in-place formwork. After that, it is possible to install a cage inside and fill the voids with concrete; see Fig. 3c.

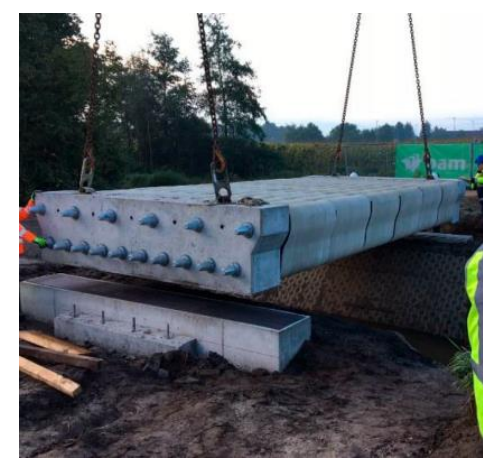

a)

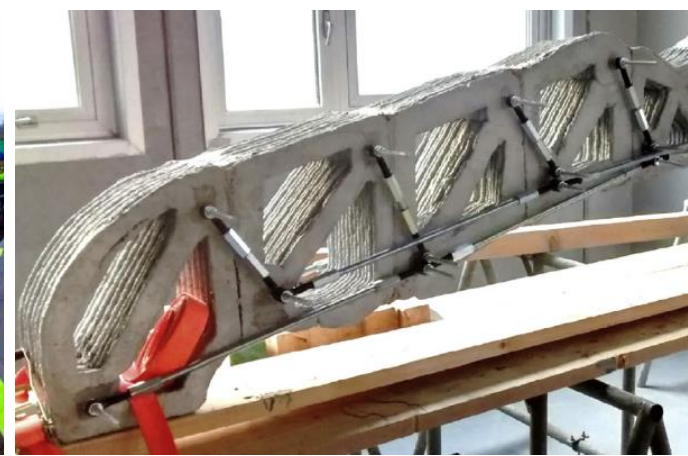

b)

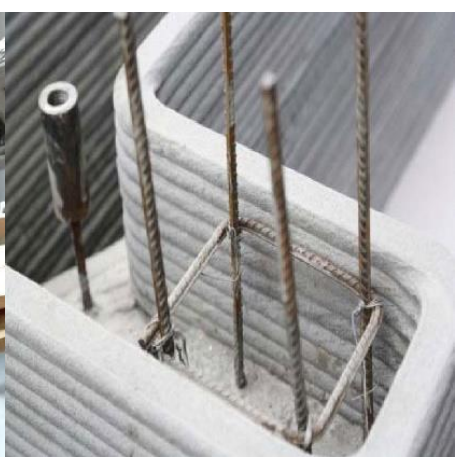

c)

Figure 3. Reinforcement integration after concrete printing with a) post-tensioned bars [34], b) external reinforcement system [36], and c) pre-fabricated cages [37].

\section{Reinforcement strategies developed at TU Dresden}

\section{Introduction of reinforcement prior to concrete printing}

A textile mesh laid on a flat surface can be used to create beams or slabs by 3D printing; see Fig. 4. Textiles do not corrode, therefore they do not require a protective layer of concrete, and the tests carried out have shown that the mesh adheres well even to relatively stiff concrete; see Fig. $4 \mathrm{a}$ and $4 \mathrm{~b}$. The advantage of this method is that reinforced beams and slabs of the required dimensions can be manufactured directly on the construction site using a 3D printer and placed in the final position after the concrete has hardened. 


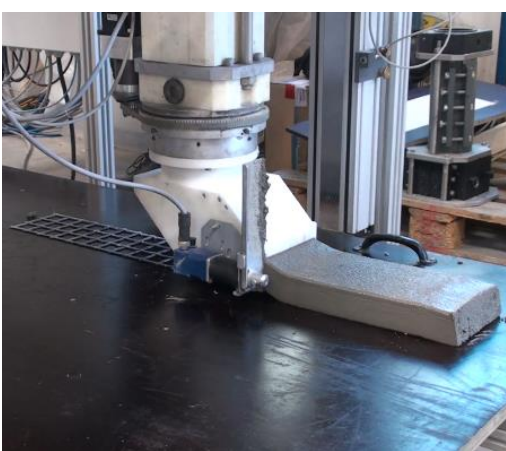

a)

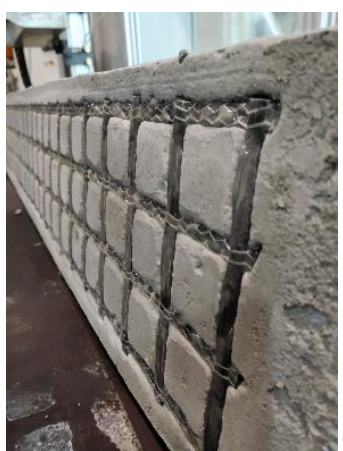

b)

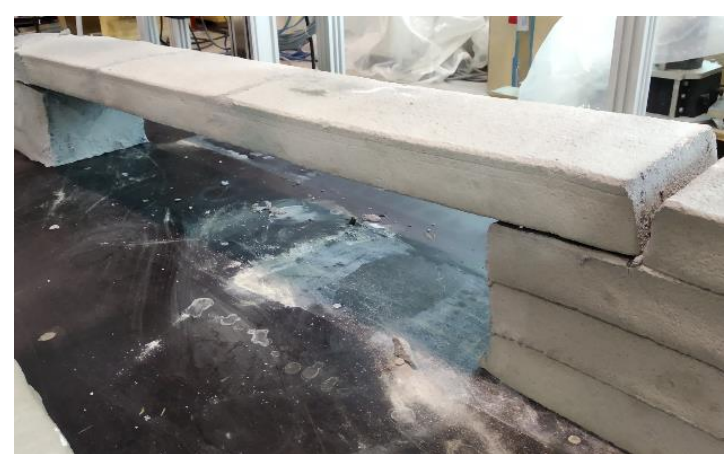

c)

Figure 4. a) Production of a textile reinforced beam using 3D concrete printing, b) bottom side of the beam, c) demonstration of the use of the beam: lintel with $800 \mathrm{~mm}$ span.

In addition to printing in horizontal layers, there are also interesting fields of application for the vertical printing direction. In preliminary tests for extrusion in the vertical direction on various substrates used as a support structure, it was possible to create surface evenness analogous to horizontally deposited elements and thus to prove the applicability of this printing method. When applying the layers to a standing coarse-meshed textile (fiber strand spacing $21 \mathrm{~mm}$ ), a slight textile penetration was achieved (see Fig. 5a), whereby a further reinforcement variant could be derived. This variant is based on an upright reinforcement cage of conventional design, but without a simultaneous two-sided concrete application. Instead, the reinforcement cage is supplemented by a textile net installed on the horizontal bars in the middle of the wall and consequently, only one-half of the wall is printed from the side of the vertical element in the first step; see Fig. $5 \mathrm{~b}$. The extrusion parameters and rheological properties of the material should be selected so that the concrete does not penetrate the textile mesh, while still providing full coverage of the steel reinforcement. This method [38] allows using a much more compact printhead and provides more degrees of freedom with regard to wall thickness and curvatures.

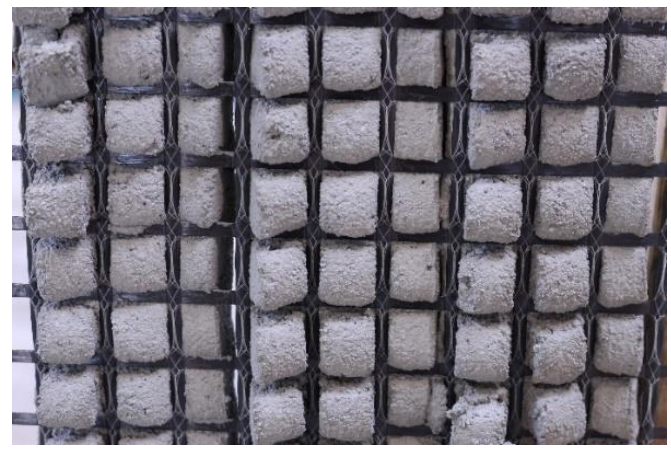

a)

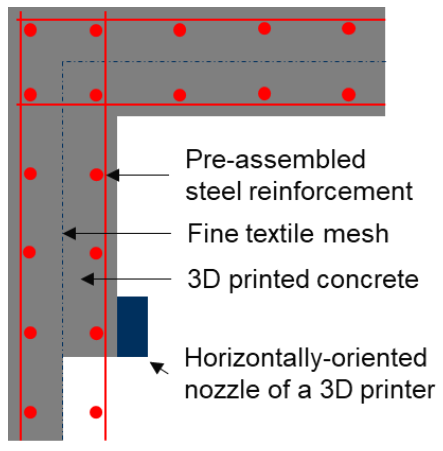

b)

Figure 5. Reinforcement with standard reinforcement cage and inner textile mesh; a) penetration of textile mesh after vertical concrete depositing, b) principal process sketch [38].

\section{Reinforcement integration during concrete printing}

The technologically most demanding approach of reinforcement integration is a fully automated reinforcement implementation directly in the printing process. For steel reinforcements, a printhead extension is currently in the development phase which connects reinforcement bar sections to underlying steel elements by means of a welding process and thereby creating a continuous reinforcement element. In this case, the concrete is poured from the two opposite sides through horizontal nozzles to ensure the cleanliness of the process zone for the next welding process. A corresponding principle sketch is shown in Fig. $6 a$. 
Another method under investigation is the printing of reinforcement in parallel with the 3D printing of concrete [39]. With Wire Arc Additive Manufacturing (WAAM) the reinforcement is gradually built up with drops of molten metal. With this technology printing of reinforcement can be fully automated, and it gives complete control over the geometry of the reinforcing bars and the ability to adjust their cross-section; see Fig. $6 \mathrm{~b}$. Based on the results of the studies carried out, it was found that the values of elastic modulus, yield stress and tensile strength of the printed steel bars are slightly lower than those of conventional steel bars, but they have a much higher strain capacity. Parallel use of 3D printing of steel and concrete is still under development, and issues such as slow welding speeds and high temperatures that can damage printed concrete have yet to be addressed. Currently, WAAM technology is also being investigated in several other research institutions, including TU Munich [40], TU Braunschweig [41], and TU Delft [42]. Lately, the use of 3D printing of steel in construction was demonstrated by MX3D company by printing a whole bridge, which was later installed in Amsterdam [43].

In order to improve the bond between the printed layers while placing horizontal reinforcement, at TU Dresden it was proposed to use 2.5D textiles [44]; see Fig. 6c. Such textiles can be very useful specifically when there is a pause in construction, which can lead to the formation of a cold joint. It is assumed that in the future the laying of such reinforcement can be automated by installing a spool with textiles on a 3D printer.

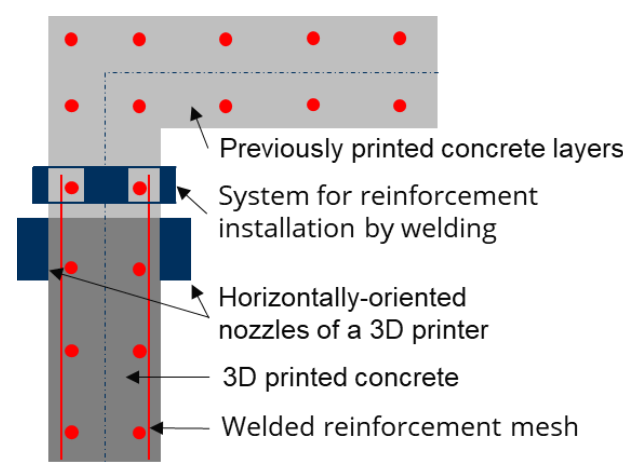

a)

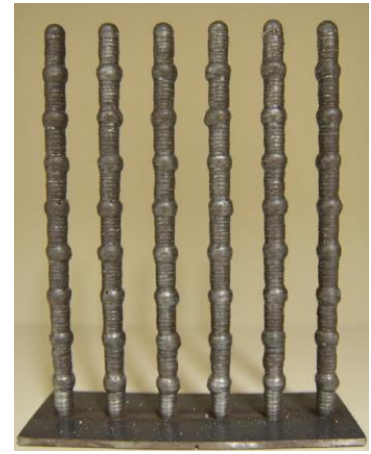

b)

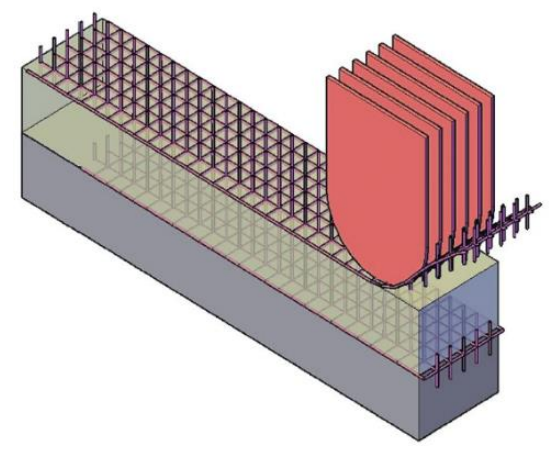

c)

Figure 6. a) Principal process sketch for installing reinforcement by welding process b) 3D printed steel bars [39], and c) illustration of 2.5D textile laying process [44].

The reinforcement with continuous carbon fibers is another investigated approach. Specially developed suspension made of micro-cement, microsilica, water, and superplasticizer [45] for impregnation of continuous fibers has many advantages over polymer impregnation of the yarns [46]. A very high technological flexibility allows the geometrical freedom of additive manufacturing to be fully exploited. The impregnated yarn can be wound onto a spool and introduced into a structure during its 3D printing following two different methods:

- Contiguous process: The yarn is placed on the already printed concrete filament and overprinted, see Fig. 7a. The advantage of this process is that the number of filaments can be varied, while also overlapping of yarns for a better transfer of tensile forces can be easily implemented. The disadvantage is that the bond in the joint is disturbed by the yarn to some extent [47].

- Simultaneous process: The yarn is inserted into layers during the printing through the openings on the back of the nozzle. Thus, the reinforcement is integrated directly into the concrete filament and deposited together; see Fig. 7b. The simultaneous process saves time and does not disturb the joint. Through openings in the back of the nozzle, up to six yarns can be integrated at the same time; see Fig. 7c. It must be taken into account that, if the consistency of an extruded material is too stiff, air pockets similar to spray shadows can occur under the reinforcement [48]. 


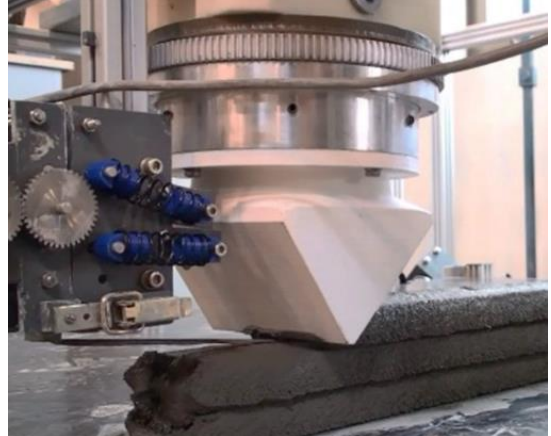

a)

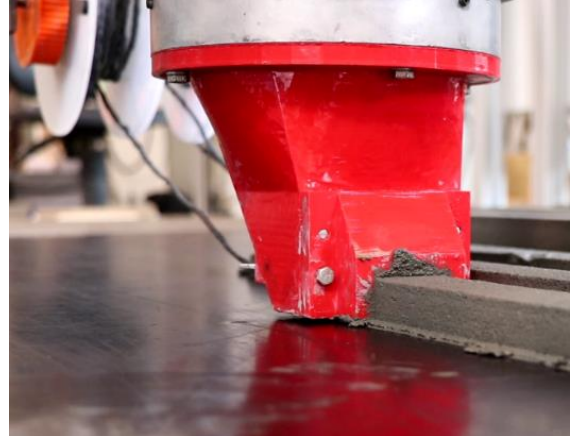

b)

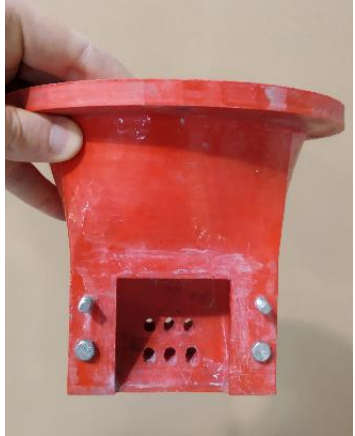

c)

Figure 7. a) Yarn is placed between the layers [47], b) yarn is integrated directly into printed layer [48], and c) nozzle geometry for integrating textile yarns into printed layers.

Strain Hardening Cementitious Composites (SHCC) are materials reinforced with short fibers and showing quasi-ductile behavior under tensile loading. SHCC can reduce the need for reinforcement or in some cases even to enable doing without it completely. Ogura et al. [49] have developed SHCC suitable for 3D printing; see Fig. 8a. According to the results of tensile tests carried out during the study, the developed material with $1.5 \%$ of fibers by volume of the composite has a tensile strength of approximately $5 \mathrm{MPa}$ and a strain capacity of approximately $3 \%$; see Fig. 8b. Later on, at the Shimizu Institute of Technology, Ogura implemented this approach under the name of Laminatable Cement-based Tough Material fiber-reinforced cement composite, that was used to print the permanent formwork for the construction of the columns with a height of $4.2 \mathrm{~m}$ [50]; see Fig. 8c. It is worth noting that investigations on printable SHCC are carried out in several research groups, the comprehensive review on the progress in this field was presented by Li et al. [51].

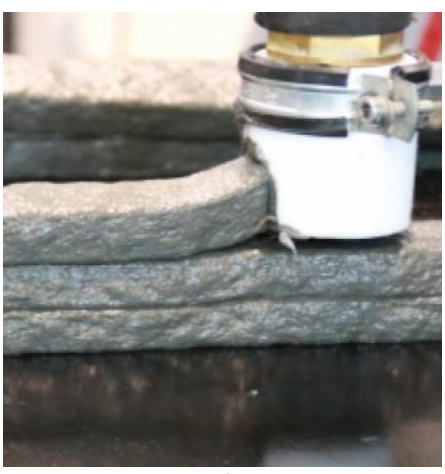

a)

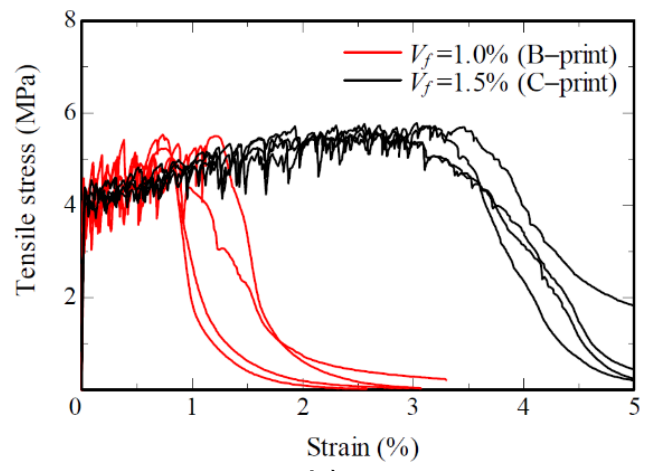

b)

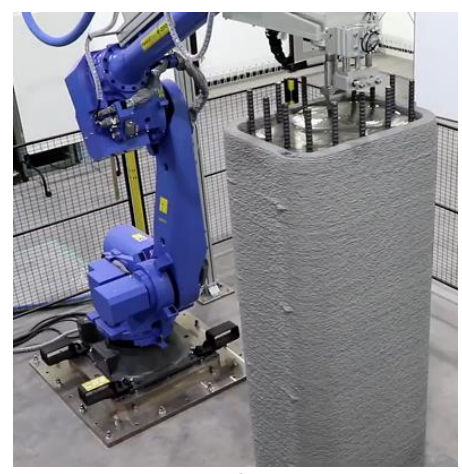

c)

Figure 8. a) 3D printing with SHCC, b) uniaxial tension tests results for a printable SHCC [49], and c) construction of a column with SHCC as a permanent formwork [50].

\section{Reinforcement integration after concrete printing}

The method of post-reinforcement of printed structures can be considered as a direct continuation of the work on the development of full-width printing technology CONPrint3D [52], but it is also suitable for contour crafting approaches. Fig. 9a presents a principle sketch. This method is technologically simple to implement, since the printing process has already been mastered, and all that remains is to place the anchors between the printed layers at certain distances. After the printed core wall has hardened, the required reinforcement can be suspended from these anchors in the form of a steel or a textile mesh; see Fig. 9b and 9c, respectively. Afterward, it can be monolithically connected to the wall by a laterally guided vertical or horizontal printing process and the final geometry of the component can be achieved. The advantage of this construction variant is due to the low demands on the machine technology and can be realized with slight adaptations with most of the printing systems com- 
monly available on the market. The disadvantages are the mostly manual fastening of the reinforcement (this process can be automated though) and the need of consecutive process steps.

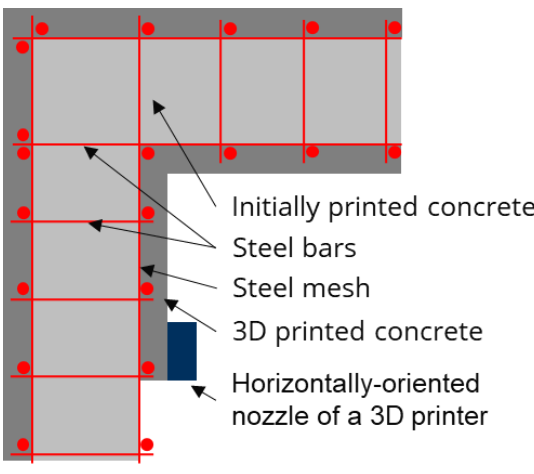

a)

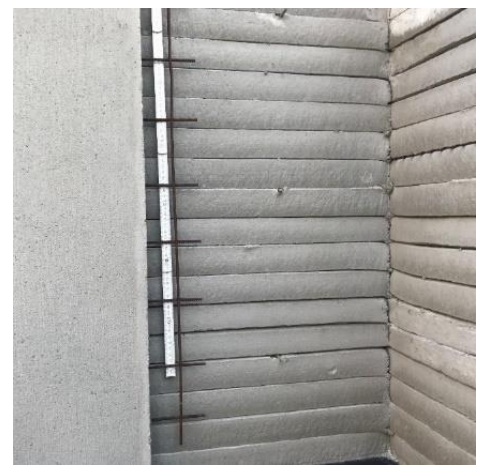

b)

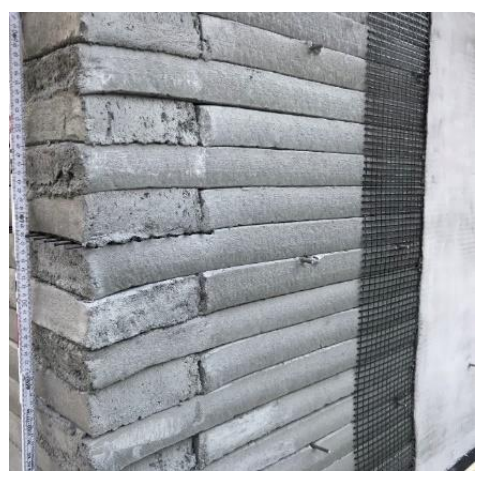

c)

Figure 9. Post-printing integration of reinforcement a) principle sketch, b) steel mesh reinforcement on the printed subgrade, and c) reinforcement with a carbon textile.

\section{Conclusion}

With the development of 3D concrete printing technology, an increasing number of various strategies for reinforcement of printed structures have appeared. This publication provides a brief overview of the existing reinforcement methods and introduces various strategies developed at TU Dresden.

As in conventional construction, 3D printed walls require reinforcement in two directions. Most of the existing strategies for reinforcement integration during concrete printing cannot provide that, therefore, they must be applied in combination with other methods. Highly automated technologies that could fully cover the need for reinforcement, namely welding of short bars and 3D printing of reinforcement using Wire Arc Additive Manufacturing, are not yet ready for practical applications and still require further research. In the meantime, installing steel reinforcement before or after 3D printing is a good alternative. As examples, this article introduces both a new strategy for the installation of reinforcement before printing using fine textile mesh, which does not require a sophisticated printhead geometry, and a new strategy for reinforcement after printing, which is easy to implement as it does not involve a high degree of automation. This article also presents a new method for the production of reinforced beams and slabs directly on the construction site by printing over a textile mesh. Furthermore, some other developed approaches for reinforcement using 2.5D textile, continuous carbon fibers, and by printing of Strain Hardening Cementitious Composites are presented.

\section{Data availability statement}

Data sharing not applicable.

\section{Author contributions}

Conceptualization, E.I. and V.M.; writing - original draft, E.I., S.M., and T.N.; writing - review \& editing, V.M.; funding acquisition - V.M.

\section{Competing interests}

The authors declare no competing interests. 


\section{Acknowledgement}

This paper is a part of the first author's PhD dissertation. The authors would like to thank the German Research Foundation (Deutsche Forschungsgemeinschaft - DFG) for financial support of the project number 424057211 "Adaptive Concrete Diamond Construction (ACDC)", within the Priority Program "Adaptive modularized constructions made in flux" (SPP 2187) and the project number 417002380 within the framework of the projects SFB/TRR 280 "Design strategies for material-minimised carbon reinforced concrete structures - Principles of a new approach to construction".

\section{References}

1. R. Maskuriy, A. Selamat, K. N. Ali, P. Maresova, and O. Krejcar, "Industry 4.0 for the Construction Industry-How Ready Is the Industry?," Appl. Sci., vol. 9, no. 14, p. 2819, 2019, doi: https://doi.org/10.3390/app9142819.

2. E. Lloret et al., "Complex concrete structures," Comput. Des., vol. 60, pp. 40-49, 2014, doi: https://doi.org/10.1016/j.cad.2014.02.011.

3. N.. Hack, "Mesh Mould : Robotically Fabricated Metal Meshes as Concrete Formwork and Reinforcement," no. September, pp. 1-13, 2015.

4. Z. Dakhli and Z. Lafhaj, "Robotic mechanical design for brick-laying automation," Cogent Eng., vol. 4, no. 1, 2017, doi: https://doi.org/10.1080/23311916.2017.1361600.

5. R. Buswell et al., "A process classification framework for defining and describing Digital Fabrication with Concrete," Cem. Concr. Res., vol. 134, no. March, 2020, doi: https://doi.org/10.1016/j.cemconres.2020.106068.

6. R. Buswell, W. R. Leal de Silva, S. Z. Jones, and J. Dirrenberger, "3D printing using concrete extrusion: A roadmap for research," Cem. Concr. Res., vol. 112, no. October 2017, pp. 37-49, 2018, doi: https://doi.org/10.1016/j.cemconres.2018.05.006.

7. N. Hack and H. Kloft, "Shotcrete 3D Printing Technology for the Fabrication of Slender Fully Reinforced Freeform Concrete Elements with High Surface Quality: A RealScale Demonstrator," RILEM Bookseries, vol. 28, no. July, pp. 1128-1137, 2020, doi: https://doi.org/10.1007/978-3-030-49916-7_107.

8. D. Lowke, E. Dini, A. Perrot, D. Weger, C. Gehlen, and B. Dillenburger, "Particle-bed 3D printing in concrete construction - Possibilities and challenges," Cem. Concr. Res., vol. 112, no. November 2017, pp. 50-65, 2018, doi: https://doi.org/10.1016/j.cemconres.2018.05.018.

9. "8 Biggest Companies Building 3D Printed Houses | All3DP Pro." https://all3dp.com/2/2019-best-companies-building-3d-printed-houses/ (accessed Sep. 15, 2021).

10. T. Wangler et al., "Digital Concrete: Opportunities and Challenges," RILEM Tech. Lett., vol. 1, p. 67, 2016, doi: https://doi.org/10.21809/rilemtechlett.2016.16.

11. V. Mechtcherine et al., "Integrating reinforcement in digital fabrication with concrete: $A$ review and classification framework," Cem. Concr. Compos., vol. 119, no. February, p. 103964, 2021, doi: https://doi.org/10.1016/j.cemconcomp.2021.103964.

12. D. Asprone, C. Menna, F. Bos, T. A. M. Salet, J. Mata-Falcón, and W. Kaufmann, "Rethinking reinforcement for digital fabrication with concrete," Cem. Concr. Res., vol. 112, no. January, pp. 111-121, 2018, doi: https://doi.org/10.1016/j.cemconres.2018.05.020.

13. V. N. Nerella, H. Ogura, and V. Mechtcherine, "Incorporating reinforcement into digital concrete construction,” Annu. IASS Symp. Creat. Struct. Des., no. July, 2018.

14. F. Bester, M. van den Heever, J. Kruger, and G. van Zijl, "Reinforcing digitally fabricated concrete: A systems approach review," Addit. Manuf., vol. 37, no. September 2020, 2021, doi: https://doi.org/10.1016/j.addma.2020.101737.

15. H. Kloft, M. Empelmann, N. Hack, E. Herrmann, and D. Lowke, " Reinforcement strategies for 3D-concrete-printing ," Civ. Eng. Des., vol. 2, no. 4, pp. 131-139, 2020, doi: https://doi.org/10.1002/cend.202000022. 
16. Paolini, S. Kollmannsberger, and E. Rank, "Additive manufacturing in construction: $A$ review on processes, applications, and digital planning methods," Addit. Manuf., vol. 30, no. October, p. 100894, 2019, doi: https://doi.org/10.1016/j.addma.2019.100894.

17. "World's first 3D-printed house that can withstand 8.0-magnitude quake - YouTube." https://www.youtube.com/watch?v=OloOc21_u80 (accessed Sep. 15, 2021).

18. P. Ayres, W. Ricardo, P. Nicholas, and T. J. Andersen, "SCRIM - Sparse Concrete Reinforcement in Meshworks," Robot. Fabr. Archit. Art Des. 2018, no. September 2018, 2019, doi: https://doi.org/10.1007/978-3-319-92294-2.

19. B. Baz, G. Aouad, P. Leblond, O. Al-Mansouri, M. D'hondt, and S. Remond, "Mechanical assessment of concrete - Steel bonding in 3D printed elements," Constr. Build. Mater., vol. 256, p. 119457, 2020, doi: https://doi.org/10.1016/j.conbuildmat.2020.119457.

20. M. Classen, J. J. , and R. Sharma, "Additive manufacturing of reinforced concretedevelopment of a 3D printing technology for cementitious composites with metallic reinforcement," Appl. Sci., vol. 10, no. 11, 2020, doi: https://doi.org/10.3390/app10113791.

21. T. Marchment and J. G. Sanjayan, "Mesh reinforcing method for 3D Concrete Printing," Autom. Constr., vol. 109, no. August 2019, p. 102992, 2020, doi: https://doi.org/10.1016/j.autcon.2019.102992.

22. W. Wang, N. Konstantinidis, S. A. Austin, R. Buswell, S. Cavalaro, and D. Cecinia, "Flexural Behaviour of AR-Glass Textile Reinforced 3D Printed Concrete Beams," in Second RILEM International Conference on Concrete and Digital Fabrication, 2020, pp. 728-737, doi: https://doi.org/10.1007/978-3-030-49916-7_73.

23. F. Bos, Z. Y. Ahmed, E. R. Jutinov, and T. A. M. Salet, "Experimental exploration of metal cable as reinforcement in 3D printed concrete," Materials (Basel)., vol. 10, no. 11, 2017, doi: https://doi.org/10.3390/ma10111314.

24. Perrot, Y. Jacquet, D. Rangeard, E. Courteille, and M. Sonebi, "Nailing of layers: A promisingway to reinforce concrete 3D printing structures," Materials (Basel)., vol. 13, no. 7, 2020, doi: https://doi.org/10.3390/ma13071518.

25. T. Marchment and J. Sanjayan, "Bond properties of reinforcing bar penetrations in 3D concrete printing," Autom. Constr., vol. 120, no. May, p. 103394, 2020, doi: https://doi.org/10.1016/j.autcon.2020.103394.

26. C. Matthäus, N. Kofler, T. Kränkel, D. Weger, and C. Gehlen, "Interlayer reinforcement combined with fiber reinforcement for extruded lightweight mortar elements," Materials (Basel)., vol. 13, no. 21, pp. 1-17, 2020, doi: https://doi.org/10.3390/ma13214778.

27. O. Geneidy, S. Kumarji, A. Dubor, and A. Sollazzo, "Simultaneous Reinforcement of Concrete While 3D Printing," in Second RILEM International Conference on Concrete and Digital Fabrication, 2020, pp. 895-905.

28. L. Hass and F. Bos, "Bending and Pull-Out Tests on a Novel Screw Type Reinforcement for Extrusion-Based 3D Printed Concrete," RILEM Bookseries, vol. 28, no. July, pp. 632-645, 2020, doi: https://doi.org/10.1007/978-3-030-49916-7_64.

29. "V2 Vesta Beton-3D-Drucker baut kleines Haus." https://3druck.com/drucker-undprodukte/v2-vesta-beton-3d-drucker-baut-kleines-haus-2846225/ (accessed Sep. 09, 2021).

30. "Rudenko 3D Printer." http://www.totalkustom.com/gallery.html (accessed Sep. 09, 2021). https://www.youtube.com/watch?app=desktop\&v=Uzg6pilf0PI\&t=275s $\quad$ (accessed

YouTube." Sep. 09, 2021).

32. M. Hambach and D. Volkmer, "Properties of 3D-printed fiber-reinforced Portland cement paste," Cem. Concr. Compos., vol. 79, pp. 62-70, 2017, doi: https://doi.org/10.1016/j.cemconcomp.2017.02.001.

33. S. Lim, R. Buswell, T. T. Le, S. A. Austin, A. G. F. Gibb, and T. Thorpe, "Developments in construction-scale additive manufacturing processes," Autom. Constr., vol. 21, no. 1, pp. 262-268, 2012, doi: https://doi.org/110.1016/j.autcon.2011.06.010. 
34. T. A. M. Salet, Z. Y. Ahmed, F. Bos, and H. L. M. Laagland, "Design of a 3D printed concrete bridge by testing," Virtual Phys. Prototyp., vol. 13, no. 3, pp. 222-236, 2018, doi: https://doi.org/10.1080/17452759.2018.1476064.

35. "An optimal concrete bridge - Department of Structural Engineering and Building Materials."

https://www.ugent.be/ea/structuralengineer-

ing/en/research/clusters/themes/digitalfabrication/projectsdigitalfabrication/3dbridge.h tm (accessed Sep. 10, 2021).

36. D. Asprone, F. Auricchio, C. Menna, and V. Mercuri, "3D printing of reinforced concrete elements: Technology and design approach," Constr. Build. Mater., vol. 165, pp. 218-231, 2018, doi: https://doi.org/10.1016/j.conbuildmat.2018.01.018.

37. "Shanghai-based WinSun 3D Prints 6-Story Apartment Building and an Incredible Home - 3DPrint.com | The Voice of 3D Printing / Additive Manufacturing." https://3dprint.com/38144/3d-printed-apartment-building/ (accessed Sep. 10, 2021).

38. "Patent Application: Technology for extrusions-based manufacturing of reinforced concrete elements," 2021012014094001DE, 2021

39. V. Mechtcherine, J. Grafe, V. N. Nerella, E. Spaniol, M. Hertel, and U. Füssel, "3Dprinted steel reinforcement for digital concrete construction - Manufacture, mechanical properties and bond behaviour," Constr. Build. Mater., vol. 179, pp. 125-137, 2018, doi: https://doi.org/10.1016/j.conbuildmat.2018.05.202.

40. D. Weger et al., "Reinforced Particle-Bed Printing by Combination of the Selective Paste Intrusion Method with Wire and Arc Additive Manufacturing -- A First Feasibility Study," in Second RILEM International Conference on Concrete and Digital Fabrication, 2020, pp. 978-987.

41. J. Müller et al., "Design and parameter identification of wire and arc additively manufactured (WAAM) steel bars for use in construction," Metals (Basel)., vol. 9, no. 7, 2019, doi: https://doi.org/10.3390/met9070725.

42. Z. Lin, C. Goulas, W. Ya, and M. J. M. Hermans, "Microstructure and mechanical properties of medium carbon steel deposits obtained via wire and arc additive manufacturing using metal-cored wire," Metals (Basel)., vol. 9, no. 6, 2019, doi: https://doi.org/10.3390/met9060673.

43. "MX3D Bridge | MX3D." https://mx3d.com/industries/infrastructure/mx3d-bridge/ (accessed Sep. 20, 2021).

44. V. Mechtcherine and V. N. Nerella, "Integration der Bewehrung beim 3D-Druck mit Beton," Beton- und Stahlbetonbau, vol. 113, no. 7, pp. 496-504, 2018, doi: https://doi.org/10.1002/best.201800003.

45. K. Schneider, A. Michel, M. Liebscher, L. Terreri, S. Hempel, and V. Mechtcherine, "Mineral-impregnated carbon fibre reinforcement for high temperature resistance of thin-walled concrete structures," Cem. Concr. Compos., vol. 97, pp. 68-77, 2019, doi: https://doi.org/10.1016/j.cemconcomp.2018.12.006.

46. V. Mechtcherine, A. Michel, M. Liebscher, K. Schneider, and C. Großmann, "Mineralimpregnated carbon fiber composites as novel reinforcement for concrete construction: Material and automation perspectives," Autom. Constr., vol. 110, no. September 2019, p. 103002, 2020, doi: https://doi.org/10.1016/j.autcon.2019.103002.

47. V. Mechtcherine, A. Michel, M. Liebscher, and T. Schmeier, "Extrusion-Based Additive Manufacturing with Carbon Reinforced Concrete: Concept and Feasibility Study," Materials (Basel)., vol. 13, no. 11, p. 2568, 2020, doi: https://doi.org/10.3390/ma13112568.

48. T. Neef, S. Müller, and V. Mechtcherine, "3D-Druck mit Carbonbeton: Technologie und die ersten Untersuchungsergebnisse," Beton- und Stahlbetonbau, vol. 115, no. 12, pp. 943-951, 2020, doi: https://doi.org/10.1002/best.202000069.

49. H. Ogura, V. N. Nerella, and V. Mechtcherine, "Developing and testing of StrainHardening Cement-Based Composites (SHCC) in the context of 3D-printing," Materials (Basel)., vol. 11, no. 8, pp. 1-18, 2018, doi: https://doi.org/10.3390/ma11081375.

50. "From the Institute of Technology Succeeding to create Massive Columns Having a Free-form Curved Surface With 3D Printing The Possibilities of 'LACTM' Fiber- 
reinforced Cement Composite | Topics | Shimizu Corporation." https://www.shimz.co.jp/en/topics/technology/item01/ (accessed Sep. 20, 2021).

51. V. C. Li et al., "On the emergence of 3D printable Engineered, Strain Hardening Cementitious Composites (ECC/SHCC)," Cem. Concr. Res., vol. 132, no. January, p. 106038, 2020, doi: https://doi.org/10.1016/j.cemconres.2020.106038.

52. V. Mechtcherine, V. N. Nerella, F. Will, M. Näther, J. Otto, and M. Krause, "Largescale digital concrete construction - CONPrint3D concept for on-site, monolithic 3Dprinting," Autom. Constr., vol. 107, no. April, p. 102933, 2019, doi: https://doi.org/10.1016/j.autcon.2019.102933. 